\title{
Inhibition of Dermatophyte Fungi by Australian Jarrah Honey
}

\author{
Annabel Guttentag ${ }^{1}$, Krishothman Krishnakumar ${ }^{1}$, Nural Cokcetin ${ }^{2} \mathbb{D}$, Steven Hainsworth ${ }^{3}$, Elizabeth Harry ${ }^{2} \mathbb{D}$ \\ and Dee Carter ${ }^{1, *(D)}$
}

1 Marie Bashir Institute, School of Life and Environmental Sciences, University of Sydney, Sydney, NSW 2006, Australia; annabel.guttentag@sydney.edu.au (A.G.); krishoth2@gmail.com (K.K.)

2 Ithree Institute, University of Technology Sydney, Sydney, NSW 2007, Australia; nural.cokcetin@uts.edu.au (N.C.); elizabeth.harry@uts.edu.au (E.H.)

3 School of Science, RMIT University, Melbourne, VIC 3083, Australia; shainsworth1591@gmail.com

* Correspondence: dee.carter@sydney.edu.au; Tel.: +61-2-9351-5383

Citation: Guttentag, A.;

Krishnakumar, K.; Cokcetin, N.; Hainsworth, S.; Harry, E.; Carter, D. Inhibition of Dermatophyte Fungi by Australian Jarrah Honey. Pathogens 2021, 10, 194. https://doi.org/ $10.3390 /$ pathogens 10020194

Academic Editor: Peter N. Lipke

Received: 12 January 2021

Accepted: 5 February 2021

Published: 11 February 2021

Publisher's Note: MDPI stays neutral with regard to jurisdictional claims in published maps and institutional affiliations.

Copyright: (c) 2021 by the authors. Licensee MDPI, Basel, Switzerland. This article is an open access article distributed under the terms and conditions of the Creative Commons Attribution (CC BY) license (https:// creativecommons.org/licenses/by/ $4.0 /)$.

\begin{abstract}
Superficial dermatophyte infections, commonly known as tineas, are the most prevalent fungal ailment and are increasing in incidence, leading to an interest in alternative treatments. Many floral honeys possess antimicrobial activity due to high sugar, low $\mathrm{pH}$, and the production of hydrogen peroxide $\left(\mathrm{H}_{2} \mathrm{O}_{2}\right)$ from the activity of the bee-derived enzyme glucose oxidase. Australian jarrah (Eucalyptus marginata) honey produces particularly high levels of $\mathrm{H}_{2} \mathrm{O}_{2}$ and has been found to be potently antifungal. This study characterized the activity of jarrah honey on fungal dermatophyte species. Jarrah honey inhibited dermatophytes with minimum inhibitory concentrations (MICs) of $1.5-3.5 \%(w / v)$, which increased to $\geq 25 \%(w / v)$ when catalase was added. Microscopic analysis found jarrah honey inhibited the germination of Trichophyton rubrum conidia and scanning electron microscopy of mature T. rubrum hyphae after honey treatment revealed bulging and collapsed regions. When treated hyphae were stained using REDOX fluorophores these did not detect any internal oxidative stress, suggesting jarrah honey acts largely on the hyphal surface. Although $\mathrm{H}_{2} \mathrm{O}_{2}$ appears critical for the antifungal activity of jarrah honey and its action on fungal cells, these effects persisted when $\mathrm{H}_{2} \mathrm{O}_{2}$ was eliminated and could not be replicated using synthetic honey spiked with $\mathrm{H}_{2} \mathrm{O}_{2}$, indicating jarrah honey contains agents that augment antifungal activity.
\end{abstract}

Keywords: honey; antifungal activity; Trichophyton rubrum; dermatophytes; hydrogen peroxide

\section{Introduction}

Dermatophytes are filamentous fungi that cause superficial infections of the hair, skin, and nails. These infections, collectively described as tineas, are some of the most prevalent fungal ailments, and it has been estimated that almost everyone will acquire an infection at some point of their lifetime [1]. Over the last few decades, the incidence of tinea of the nails (onychomycosis) has risen from $2 \%$ to $14 \%$ in the developed world [2], and tinea pedis or athletes foot has increased to around 20-25\% of all adults [3]. Many factors have been implicated in this rising incidence, including increasing travel, pet ownership, and sporting facility use, along with an aging population [3]. The long duration of many dermatophyte infections presents a significant morbidity burden, especially for vulnerable groups like athletes and military personnel [4].

Currently, around 500 million USD is spent annually worldwide on antifungal therapies for tineas [1]. Treatment can be either systemic or topical, with the latter favoured due to easier self-administration and less severe side-effects [5,6]. However, these therapies often take weeks to months with daily or twice-daily applications, and relapse is common [6]. These limitations have stimulated interest in novel tinea therapies, including the use of natural products.

Honey has been used in cosmetics and medicines as an antimicrobial, emollient, and humectant since ancient times, and is still used extensively in a variety of modern 
cosmetics, with some recent licensing of sterilized honey for clinical use [7]. The antimicrobial effects of honey have been reported for a wide range of fungi [8] and bacteria [9-11]. Honey is a supersaturated sugar solution of glucose and fructose sugars, and it also contains a diverse range of proteins of bee and plant origin, as well as pigmented and antioxidant compounds including polyphenols, flavonoids, and Maillard reaction products [12-15]. Various components of honey give it antimicrobial properties, including high sugar and low $\mathrm{pH}$. The most significant antimicrobial activity is attributed to either the production of hydrogen peroxide $\left(\mathrm{H}_{2} \mathrm{O}_{2}\right)$ or to "non-peroxide" nectar-derived chemicals. $\mathrm{H}_{2} \mathrm{O}_{2}$, a powerful oxidant, is produced by glucose oxidase, a bee-derived enzyme that is activated upon dilution of honey with water [15]. "Non-peroxide" honeys generally originate from manuka plants of the Leptospermum genus and contain methylglyoxal (MGO), a toxic compound that crosslinks and inhibits microbial proteins [16,17]. Additional non-peroxide floral factors include phenolic compounds and peptides. The standard methodology to differentiate between these two types of antimicrobial activity is to treat honey with a catalase solution, which abolishes $\mathrm{H}_{2} \mathrm{O}_{2}$ activity, while the "non-peroxide" activity remains [8,18].

Honey is a promising candidate for the prolonged, topical treatment of superficial infections like tinea due to its broad-spectrum antimicrobial properties and its low toxicity. Previous studies have shown that unpasteurized $\mathrm{H}_{2} \mathrm{O}_{2}$-producing honeys from New Zealand and Iran were able to inhibit a range of dermatophyte species $[19,20]$. Australia has diverse and unique native flora, and numerous Australian honeys exhibit high $\mathrm{H}_{2} \mathrm{O}_{2}$ based antibacterial activity, especially those of Eucalyptus marginata (jarrah) origin [21].

This study set out to characterize the antifungal activity of selected Australian honeys against dermatophytes, with a focus on jarrah honey. We show here that jarrah honey was potently antifungal, inhibiting conidial germination and damaging hyphal structures. Unexpectedly, oxidative stress was not observed in the treated hyphae, and the estimated level of $\mathrm{H}_{2} \mathrm{O}_{2}$ produced in diluted honey was insufficient to account for the level of antifungal activity that was observed.

\section{Results}

2.1. Minimum Inhibitory Concentrations (MICs) and Minimum Antifungal Concentrations (MFCs) for Dermatophytes Treated with Jarrah, Leptospermum and Artificial Honey

MIC testing was undertaken for Jarrah 2017, Leptospermum and artificial honey, with the antifungal voriconazole (VOR) used as a control for the testing protocol. Jarrah 2017 and Leptospermum honey had broad antifungal activity against the collection of dermatophyte species, which was not seen when artificial honey, which replicates the high level of sugar found in honey, was used (Table 1). Jarrah 2017 honey produced the lowest MICs and MFCs, suggesting dermatophytes are particularly susceptible to peroxide activity.

Table 1. Antifungal activity of different honey types on a collection of dermatophyte species.

\begin{tabular}{|c|c|c|c|c|c|c|c|}
\hline \multirow{3}{*}{ Species } & \multicolumn{6}{|c|}{ Honey $(\%(w / v))$} & \multirow{3}{*}{$\begin{array}{c}\operatorname{VOR}^{3} \\
\operatorname{MIC}_{80}(\mu \mathrm{g} / \mathrm{mL})\end{array}$} \\
\hline & \multicolumn{2}{|c|}{ Jarrah 2017} & \multicolumn{2}{|c|}{ Leptospermum } & \multicolumn{2}{|c|}{ Artificial } & \\
\hline & $\mathrm{MIC}_{80}{ }^{1}$ & MFC $^{2}$ & $\mathrm{MIC}_{80}$ & MFC & $\mathrm{MIC}_{80}$ & MFC & \\
\hline Microsporum canis & 1.5 & 2 & 7.5 & 10 & 20 & $>50$ & 0.023 \\
\hline Microsporum nanum & 1.5 & 2 & 10 & 10 & 30 & $>50$ & 0.031 \\
\hline Nannizzia gypsea & 3.5 & 5 & 15 & 25 & 40 & $>50$ & 0.094 \\
\hline Trichophyton interdigitale & 3.5 & 5 & 15 & 17.5 & 40 & $>50$ & 0.125 \\
\hline Trichophyton rubrum & 2.5 & 4 & 10 & 12.5 & 30 & $>50$ & 0.031 \\
\hline Trichophyton tonsurans & 2.5 & 3.5 & 10 & 10 & 30 & $>50$ & 0.125 \\
\hline
\end{tabular}

${ }^{1}$. $\mathrm{MIC}_{80}=$ Minimum Inhibitory Concentration of the antimicrobial agent producing an $80 \%$ reduction in fungal growth relative to untreated control $;{ }^{2}$. MFC $=$ Minimum Fungicidal Concentration; ${ }^{3} . \mathrm{VOR}=$ voriconazole.

When tested with additional Australian $\mathrm{H}_{2} \mathrm{O}_{2}$-producing honeys, the dermatophyte species Nannizzia gypsea, Trichophyton interdigitale, and Trichophyton rubrum were all very susceptible with MICs of $1.56-4.2 \%(w / v)$ honey (Table 2). The addition of catalase 
(7000 U/mL) to honey dilutions substantially increased the MICs for these species across different peroxide-types honeys, although for T. rubrum and N. gypsea an MIC of $25 \%(w / v)$ was still achievable (Table 2). This suggests that $\mathrm{H}_{2} \mathrm{O}_{2}$ production is critical for the potent antifungal activity of these honeys.

Table 2. Effect of catalase treatment on the antifungal properties of jarrah and stringybark honey.

\begin{tabular}{ccccccc}
\hline & \multicolumn{5}{c}{ MIC $_{\mathbf{1 0 0}}[\mathbf{\%}(\boldsymbol{w} / \mathbf{v})]$} \\
\cline { 2 - 7 } & \multicolumn{3}{c}{ Jarrah (Barnes 10+) } & \multicolumn{1}{c}{ Jarrah 10/13 } & \multicolumn{2}{c}{ Stringybark 19 } \\
\cline { 2 - 7 } Catalase Treatment & - & + & - & + & - & + \\
\hline Nannizzia gypsea & 3.1 & 25 & 1.56 & 25 & 3.1 & 25 \\
Trichophyton interdigitale & 3.1 & $\geq 25$ & 1.56 & $\geq 25$ & $4.2 \pm 1.0$ & $>25$ \\
Trichophyton rubrum & 1.56 & 25 & 1.56 & 25 & 1.56 & 25 \\
\hline
\end{tabular}

\subsection{Estimation of $\mathrm{H}_{2} \mathrm{O}_{2}$ Production by Jarrah (Barnes 10+) Honey}

Jarrah (Barnes 10+) honey had a high level of antifungal activity (Table 2) but relatively low levels of $\mathrm{H}_{2} \mathrm{O}_{2}$ production ([22]; Table 3). This honey was chosen for extended testing as its low $\mathrm{H}_{2} \mathrm{O}_{2}$ levels but high activity meant we could analyze the mode of activity of Jarrah honey without excess damage due to $\mathrm{H}_{2} \mathrm{O}_{2}$ production. Based on our estimate that $25 \%(w / v)$ Jarrah (Barnes 10+) honey produces $\sim 448 \mu \mathrm{M}$ of $\mathrm{H}_{2} \mathrm{O}_{2}$ at $1 \mathrm{~h}$ ([22]) we calculated the concentration of $\mathrm{H}_{2} \mathrm{O}_{2}$ present in $1 \times \mathrm{MIC}$ for T. rubrum $(1.56 \%[w / v])$ to be $\sim 28 \mu \mathrm{M}$ (Table S1).

Table 3. Honey samples used in this study.

\begin{tabular}{ccccc}
\hline Honey Sample & Floral Source & Active Component & $\begin{array}{c}\text { Maximum Hydrogen } \\
\text { Peroxide } \mathbf{H}_{\mathbf{2}} \mathbf{O}_{\mathbf{2}} \mathbf{)} \\
\text { Production (mM) }\end{array}$ & Origin \\
\hline Jarrah 10 & Eucalyptus marginata & $\mathrm{H}_{2} \mathrm{O}_{2}$ & $2.86 \pm 0.31$ & {$[21]$} \\
Jarrah 13 & Eucalyptus marginata & $\mathrm{H}_{2} \mathrm{O}_{2}$ & $3.84 \pm 0.24$ & {$[21]$} \\
Stringybark 19 & Eucalyptus species & $\mathrm{H}_{2} \mathrm{O}_{2}$ & $0.93 \pm 0.12$ & {$[21]$} \\
Leptospermum 2 & Leptospermum speciosum & $\mathrm{MGO}^{2}$ & - & UTS honey collection \\
Jarrah (Barnes 10+) & Eucalyptus marginata & $\mathrm{H}_{2} \mathrm{O}_{2}$ & $0.136 \pm 0.01$ & Commercial \\
Jarrah 2017 & Eucalyptus marginata & $\mathrm{H}_{2} \mathrm{O}_{2}$ & $1.59 \pm 0.18$ & Capilano \\
\hline
\end{tabular}

\subsection{Microscopic Examination of the Effect of Jarrah Honey on T. rubrum Conidia and Their Germination}

In order to explore the effect of jarrah honey and the production of $\mathrm{H}_{2} \mathrm{O}_{2}$ on T. rubrum, we created a series of osmolarity-balanced honey solutions for Jarrah (Barnes 10+) from $\frac{1}{2}-4 \times$ MIC with artificial honey added to a final concentration of $10 \%(w / v)$ (Table 4 ). Similarly, we made a series of Synthetic $\mathrm{H}_{2} \mathrm{O}_{2}$ Honey solutions from $\frac{1}{2}-4 \times$ MIC for pure $\mathrm{H}_{2} \mathrm{O}_{2}$ (where the $\mathrm{MIC}=340 \mu \mathrm{M}$ ), a second series of $0,25,50,100,200$, and $400 \mu \mathrm{M} \mathrm{H}_{2} \mathrm{O}_{2}$ to test lower $\mathrm{H}_{2} \mathrm{O}_{2}$ levels, and a solution containing $56 \mu \mathrm{M} \mathrm{H}_{2} \mathrm{O}_{2}$ (which we calculated to be present in 2× MIC Jarrah [Barnes 10+] honey; Table S1). These were also adjusted to an osmolarity of $10 \%(w / v)$ honey using artificial honey. A final set of Jarrah (Barnes 10+) + Catalase + Artificial honeys were created where catalase $(7000 \mathrm{U} / \mathrm{mL})$ was added to Jarrah (Barnes 10+) honey and adjusted to $10 \%(w / v)$ honey using artificial honey. The figures in the results where these different honey solutions were used are listed in Table 4.

Calcofluor white staining of the fungal cell wall was used to investigate whether $\mathrm{H}_{2} \mathrm{O}_{2}$ and honey affected conidia and their germination. T. rubrum conidia treated for $48 \mathrm{~h}$ with Jarrah (Barnes 10+) honey (containing artificial honey to standardize osmolarity; Table 4) or Synthetic $\mathrm{H}_{2} \mathrm{O}_{2}$ Honey at $\frac{1}{2}, 1,2$ and $4 \times$ MIC had very limited or no germination and were 3-7 $\mu \mathrm{M}$ long, while untreated conidia produced long germ tubes of up to $60 \mu \mathrm{M}$ (Figure 1a; left and middle panels). 
Table 4. Honey solutions created to test a range of concentrations of Jarrah (Barnes 10+) honey and $\mathrm{H}_{2} \mathrm{O}_{2}$ based on the MIC for T. rubrum while keeping osmolarity consistent at $10 \%(w / v)$ honey.

\begin{tabular}{|c|c|c|c|c|c|}
\hline \multirow{3}{*}{ Honey Solution } & \multicolumn{4}{|c|}{ Final Concentration of Components in RPMI-1640 } & \multirow[t]{3}{*}{ Figures } \\
\hline & Artificial Honey & Jarrah (Barnes 10+) Honey & $\mathrm{H}_{2} \mathrm{O}_{2}$ & Catalase & \\
\hline & {$[\%(w / v)]$} & {$[\%(w / v)]$} & {$[\mu \mathrm{M}]$} & $+1-$ & \\
\hline \multicolumn{6}{|l|}{ Control } \\
\hline Untreated & 10 & 0 & 0 & - & Figure 1, Figure 2 \\
\hline \multicolumn{6}{|l|}{ Jarrah (Barnes 10+) + Artificial Honey } \\
\hline$\frac{1}{2} \times$ MIC & 9.22 & 0.78 & 0 & - & Figure 1, Figure 2 \\
\hline $1 \times \mathrm{MIC}$ & 8.44 & 1.56 & 0 & - & $\begin{array}{l}\text { Figure 1, Figure 2, } \\
\text { Figure } 3\end{array}$ \\
\hline $2 \times \mathrm{MIC}$ & 6.88 & 3.12 & 0 & - & $\begin{array}{l}\text { Figure 1, Figure 2, } \\
\text { Figure } 3\end{array}$ \\
\hline $4 \times \mathrm{MIC}$ & 3.76 & 6.24 & 0 & - & Figure 1, Figure 2a,b, \\
\hline \multicolumn{6}{|l|}{ Synthetic $\mathrm{H}_{2} \mathrm{O}_{2}$ Honey } \\
\hline$\frac{1}{2} \times$ MIC & 10 & 0 & 215 & - & Figure 1 , Figure $2 \mathrm{~b}-\mathrm{e}$ \\
\hline $1 \times \mathrm{MIC}$ & 10 & 0 & 430 & - & Figure 1 \\
\hline $2 \times \mathrm{MIC}$ & 10 & 0 & 860 & - & Figure 1 \\
\hline $4 \times \mathrm{MIC}$ & 10 & 0 & 1720 & - & Figure 1, Figure 2a \\
\hline $0 \mu \mathrm{M}$ & 10 & 0 & 0 & - & Figure 1a \\
\hline $25 \mu \mathrm{M}$ & 10 & 0 & 25 & - & Figure 1a \\
\hline $50 \mu \mathrm{M}$ & 10 & 0 & 50 & - & Figure 1a \\
\hline $100 \mu \mathrm{M}$ & 10 & 0 & 100 & - & Figure 1a \\
\hline $200 \mu \mathrm{M}$ & 10 & 0 & 200 & - & Figure 1a \\
\hline $400 \mu \mathrm{M}$ & 10 & 0 & 400 & - & Figure 1a \\
\hline $56 \mu \mathrm{M} \mathrm{H}_{2} \mathrm{O}_{2}$ & 10 & 0 & 56 & - & Figure 2c,e, Figure 3 \\
\hline \multicolumn{6}{|l|}{ Jarrah (Barnes $10+)+$ Catalase + Artificial Honey } \\
\hline Control (Artificial honey + Catalase) & 10 & 0 & 0 & + & Figure 3 \\
\hline 1× MIC Jarrah (Barnes 10+) Honey + Catalase & 8.44 & 1.56 & 0 & + & Figure 3 \\
\hline $2 \times$ MIC Jarrah (Barnes 10+) Honey + Catalase & 6.88 & 3.12 & 0 & + & Figure 3 \\
\hline
\end{tabular}

As the MIC for Synthetic $\mathrm{H}_{2} \mathrm{O}_{2}$ Honey $(430 \mu \mathrm{M}$; Table 4) was substantially higher than the concentration that was calculated to be present in $1 \times$ MIC for Jarrah (Barnes 10+) honey $(\sim 28 \mu \mathrm{M})$, a range of concentrations that encompassed the latter were tested for their ability to inhibit conidial germination. Synthetic $\mathrm{H}_{2} \mathrm{O}_{2}$ Honey concentrations of $25 \mu \mathrm{M}$, $50 \mu \mathrm{M}$, and $100 \mu \mathrm{M}$ were unable to inhibit germination compared to the untreated sample ( $p>0.42$ for all comparisons) (Figure 1a; right panel), and inhibition was only achieved at concentrations of $200 \mu \mathrm{M}$ and $400 \mu \mathrm{M}(p<0.001)$. Representative images showing the effect of Jarrah (Barnes 10+) and Synthetic $\mathrm{H}_{2} \mathrm{O}_{2}$ Honey on conidial germination are shown in Figure $1 b$.

\subsection{Analysis of Oxidative Stress in Fungal Hyphae Following Treatment with Jarrah (Barnes 10+) Using DCFDA and CellROX Green}

Catalase treatment substantially increased the MICs of the peroxide honeys suggesting that their antifungal action is dependent on $\mathrm{H}_{2} \mathrm{O}_{2}$ (Table 2). Levels of $\mathrm{H}_{2} \mathrm{O}_{2}$ and other intracellular reactive oxygen species (ROS) that exceed cellular antioxidant defences can result in temporary or permanent oxidative changes to cellular structures including lipids, proteins and DNA [23,24]. To test whether intracellular ROS was generated from honey treatment we used two fluorophores sensitive to oxidative species: DCFDA and CellROX Green. Six and $14.5 \mathrm{~h}$ were chosen for treatment as most $\mathrm{H}_{2} \mathrm{O}_{2}$ production occurs within the first $1-6 \mathrm{~h}$ of honey dilution, and at $14.5 \mathrm{~h}$ any gradual build-up of oxidative stress should become apparent [25]. 
(a)
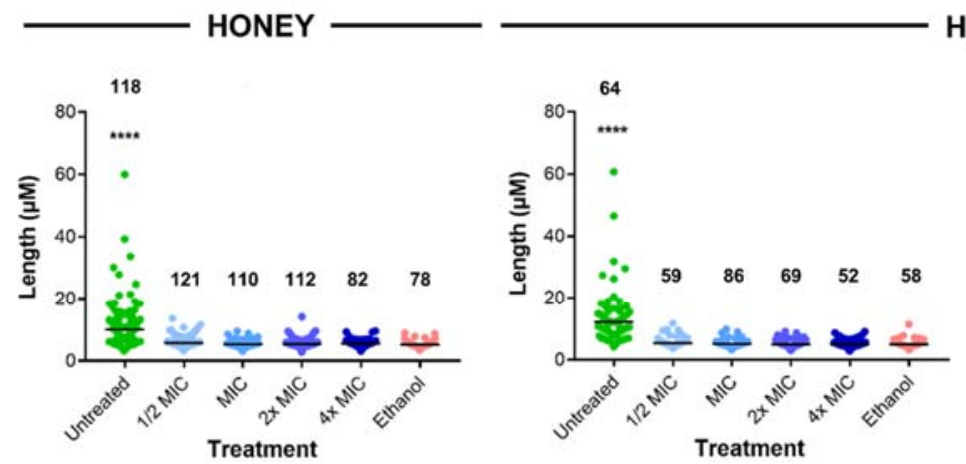

$\mathrm{H}_{2} \mathrm{O}_{2}$

(b)
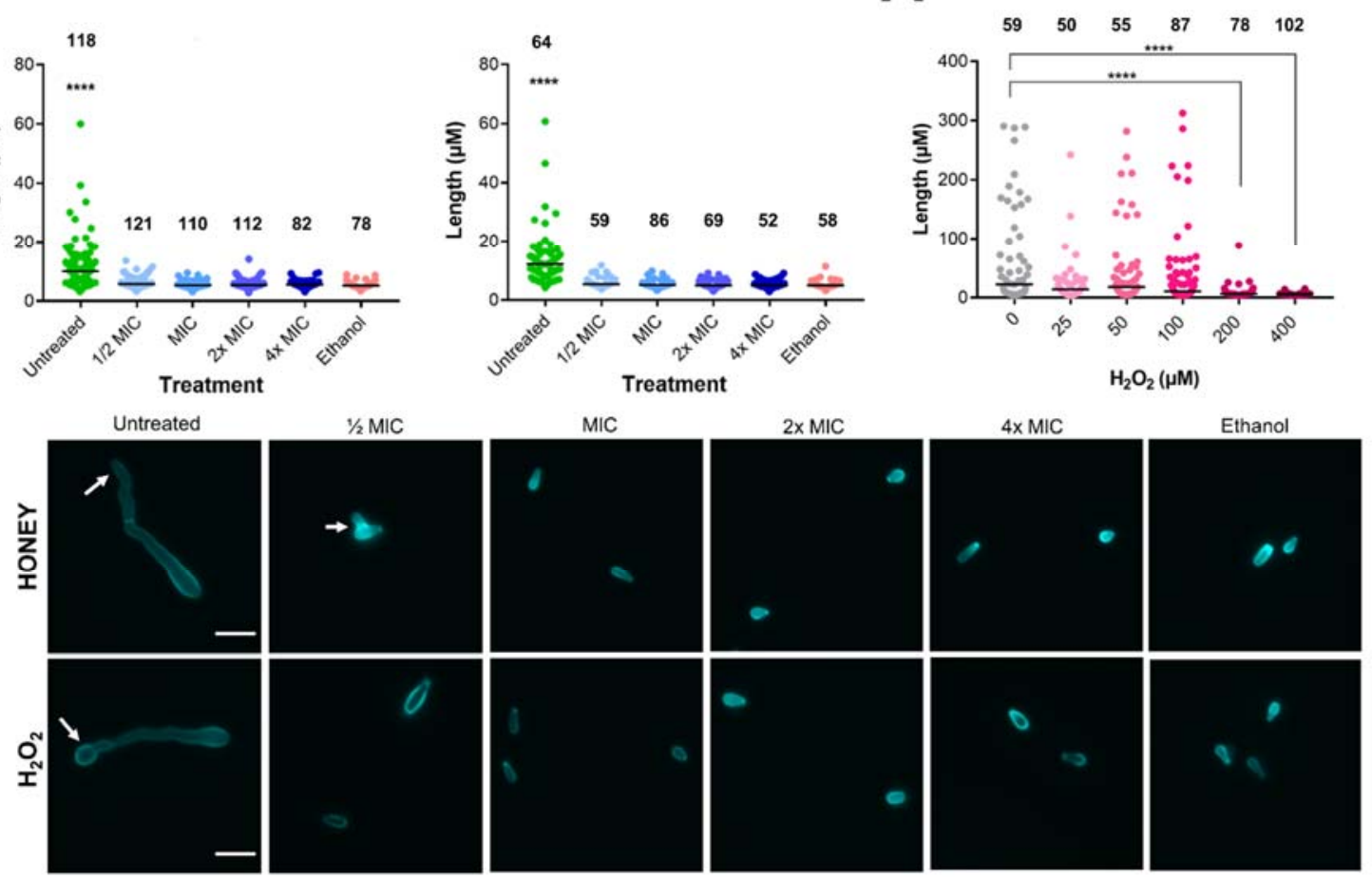

Figure 1. Jarrah (Barnes 10+) honey and Synthetic $\mathrm{H}_{2} \mathrm{O}_{2}$ Honey inhibit the germination of T. rubrum conidia. (a) Length of hyphae and conidia following treatment for $48 \mathrm{~h}$ with $\frac{1}{2} \times$ MIC $-4 \times$ MIC of Jarrah (Barnes 10+) honey (left), $\frac{1}{2} \times$ MIC $-4 \times$ MIC of Synthetic $\mathrm{H}_{2} \mathrm{O}_{2}$ Honey (middle) or Synthetic $\mathrm{H}_{2} \mathrm{O}_{2}$ Honey starting at around the level estimated to be present in Jarrah (Barnes 10+) honey (right). $\frac{1}{2} \times$ MIC levels of Jarrah (Barnes 10+) and $\frac{1}{2} \times$ MIC Synthetic $\mathrm{H}_{2} \mathrm{O}_{2}$ Honey completely suppressed conidial germination, however, Synthetic $\mathrm{H}_{2} \mathrm{O}_{2}$ Honey that contained a level of $\mathrm{H}_{2} \mathrm{O}_{2}$ calculated to be close to that present in $1 \times$ MIC Jarrah (Barnes $10+)$ honey $(25 \mu \mathrm{M})$ was not able to do this, with suppression seen only when the concentration was $\geq 200 \mu \mathrm{M}$. Ethanol at $70 \%(v / v)$ was used as a positive control. Bars represent the median and numbers above the data indicate the number of hyphae/conidia measured. Data in the left and middle panels are representative of two independent replicates. (b) Representative images of conidia and hyphae stained with calcofluor white following treatment with Jarrah (Barnes 10+) honey (top row) or Synthetic $\mathrm{H}_{2} \mathrm{O}_{2}$ Honey (bottom row). Arrows indicate germinated conidia. The scale bar represents $10 \mu \mathrm{m} .{ }^{* * * *} p \leq 0.0001$.

Representative images of stained hyphae are shown in Figure 2a. At 6 h, no DCFDA fluorescence was observed in the untreated control, while fluorescence was observed in the $4 \times$ MIC Synthetic $\mathrm{H}_{2} \mathrm{O}_{2}$ Honey treatment. None of the Jarrah (Barnes $10+$ ) treatments, ranging from $\frac{1}{2} \times \mathrm{MIC}$ to $4 \times \mathrm{MIC}$, showed any DCFDA fluorescence.

A longer treatment time of $14.5 \mathrm{~h}$ was then employed to detect any accumulation of oxidative stress, and this was detected using DCFDA (Figure 2b,d) and CellROX Green (Figure 2c,e). The Synthetic $\mathrm{H}_{2} \mathrm{O}_{2}$ Honey control was reduced to $\frac{1}{2} \times \mathrm{MIC}(215 \mu \mathrm{M})$ to prevent hyphal death that might result in increased oxidative stress. Unlike the 6-h treatment, at $14.5 \mathrm{~h}$ the hyphae treated with $4 \times$ MIC Jarrah (Barnes $10+$ ) honey had significantly more DCFDA fluorescence than the untreated control (Figure $2 \mathrm{~b}, \mathrm{~d} ; p<0.001$ ) indicating that the honey was not inhibiting DCFDA fluorescence. There was no difference in DCFDA fluorescence between the other honey treatment concentrations and the untreated sample ( $p \geq 0.5$ for all comparisons). Hyphae treated with $\frac{1}{2} \times$ MIC Synthetic $\mathrm{H}_{2} \mathrm{O}_{2}$ Honey had substantially more DCFDA fluorescence than the untreated sample (Figure $2 \mathrm{~d} ; p<0.001$ ).

CellROX Green binds irreversibly to DNA so cannot be lost from the hyphae, unlike DCFDA, which is membrane permeable. After $14.5 \mathrm{~h}$ of treatment, there was significantly more CellROX Green fluorescence in the $\frac{1}{2} \times$ MIC Synthetic $\mathrm{H}_{2} \mathrm{O}_{2}$ Honey $(215 \mu \mathrm{M})$ treatment than in the untreated control $(p<0.001)$ (Figure $2 \mathrm{c}, \mathrm{e})$. Synthetic $\mathrm{H}_{2} \mathrm{O}_{2}$ Honey containing $56 \mu \mathrm{M} \mathrm{H}_{2} \mathrm{O}_{2}$ was also tested, as this is the concentration estimated to be present in 2× MIC Jarrah (Barnes 10+) honey ([22]; Table S1). The sub-inhibitory concentrations of 
$\mathrm{H}_{2} \mathrm{O}_{2}$ caused significantly more oxidative stress in hyphae compared to the untreated sample $(p<0.0001)$. There was no difference in CellROX fluorescence between the untreated, $\frac{1}{2} \times$ MIC and $1 \times$ MIC Jarrah (Barnes 10+) honey treatments, and the $2 \times$ MIC Jarrah (Barnes $10+$ ) honey treatment had less fluorescence than the other treatments (Figure 2e).

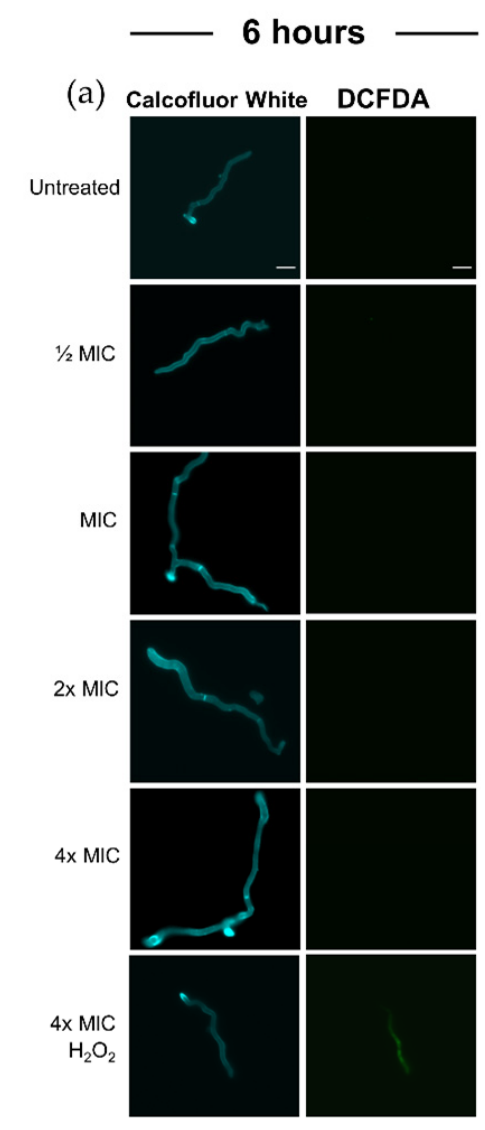

(d)

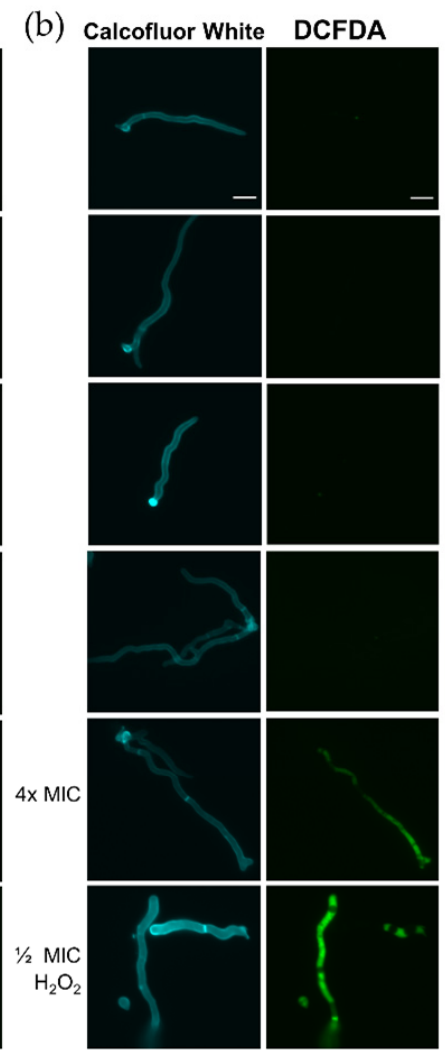

\section{5 hours}

(c)

Calcofluor White CellRox Green
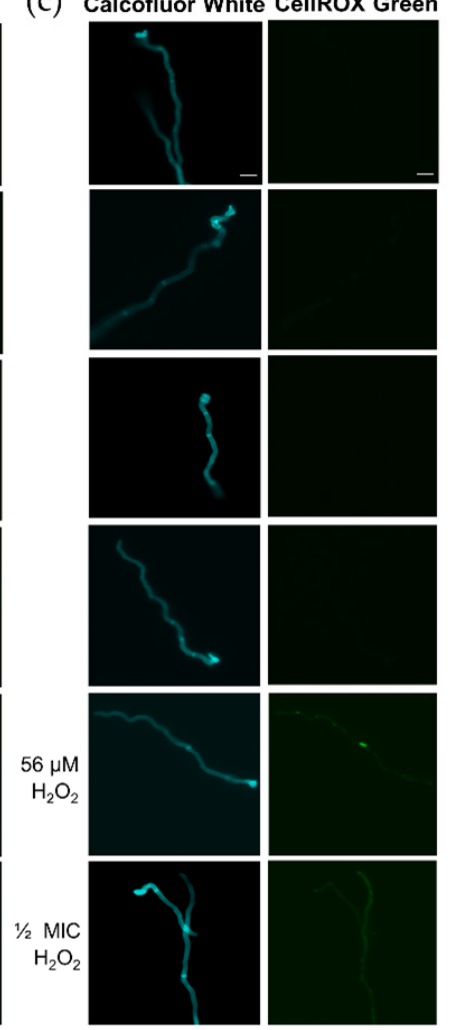

(e)

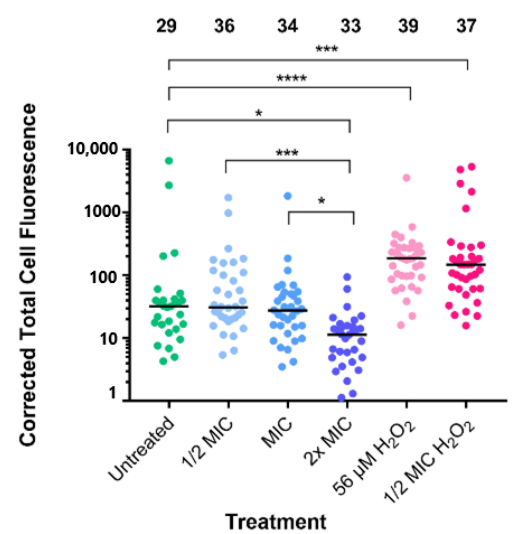

Treatment

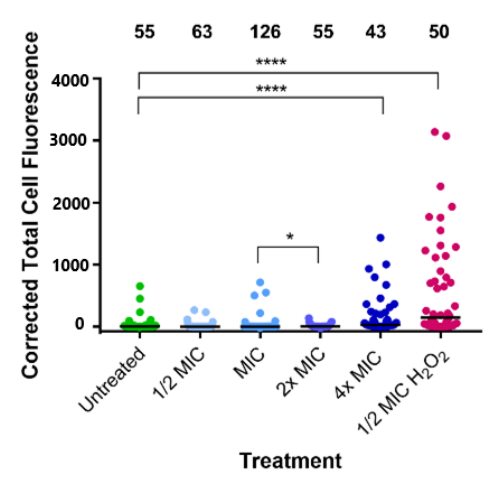

Treatment

Figure 2. Inhibitory concentrations of Jarrah (Barnes 10+) honey do not induce intracellular oxidative stress. Representative images of calcofluor white fluorescence and (a) $2^{\prime}, 7^{\prime}$-dichlorofluorescin diacetate (DCFDA) fluorescence of hyphae after $6 \mathrm{~h}$, (b) DCFDA fluorescence after $14.5 \mathrm{~h}$ and (c) CellROX Green fluorescence after $14.5 \mathrm{~h}$. Synthetic $\mathrm{H}_{2} \mathrm{O}_{2}$ Honey at $\frac{1}{2} \times$ and $4 \times$ MIC were used as positive controls for intracellular oxidative stress. The scale bars represent $10 \mu \mathrm{m}$. Corrected total cell fluorescence of (d) DCFDA and (e) CellROX Green for hyphae treated for $14.5 \mathrm{~h}$ indicate significant differences between treatments. Note that for (e) the $Y$-axis is a log scale and therefore three values close to zero could not be graphed but were included in the statistical calculations. Bars indicate the median and numbers above the data indicate the number of hyphae measured (n). ${ }^{*} p \leq 0.05$, ${ }^{* * *} p \leq 0.001{ }^{* * * *} p \leq 0.0001$. 


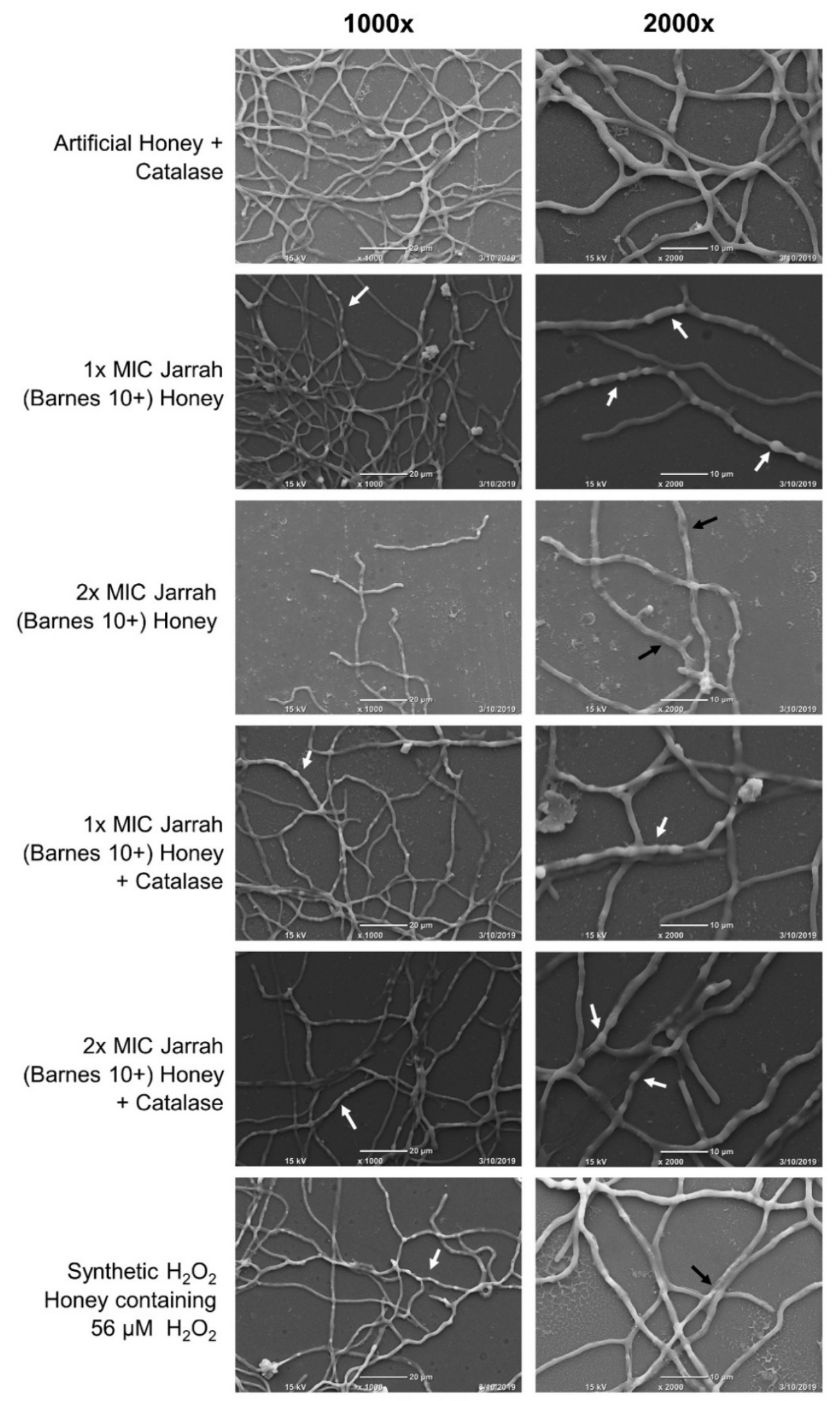

Figure 3. Trichophyton rubrum hyphae treated with Jarrah (Barnes 10+) honey have morphological deformities that are distinct from treatment with Synthetic $\mathrm{H}_{2} \mathrm{O}_{2}$ Honey and are not prevented by catalase. Hyphae grown for $24 \mathrm{~h}$ were treated with Jarrah (Barnes 10+) honey, Jarrah (Barnes 10+) honey + catalase, or Synthetic $\mathrm{H}_{2} \mathrm{O}_{2}$ Honey containing $56 \mu \mathrm{M} \mathrm{H}_{2} \mathrm{O}_{2}$ (the concentration estimated to be present in $2 \times$ MIC Jarrah [Barnes 10+] honey). Representative photos of hyphae taken at $1000 \times$ and $2000 \times$ magnification. White arrows indicate regions of hyphal ballooning and black arrows show areas of hyphal collapse. 


\subsection{Analysis of T. rubrum Hyphae Treated with Jarrah Honey by Scanning Electron Microscopy}

Scanning electron microscopy was used to determine whether treatment with Jarrah (Barnes 10+) honey (with or without catalase; Table 4) or Synthetic $\mathrm{H}_{2} \mathrm{O}_{2}$ Honey causes structural changes to T. rubrum hyphae. Hyphae treated with artificial honey containing catalase exhibited smooth, uniform surfaces (Figure 3). In comparison, treatment with Jarrah (Barnes 10+) honey at $1 \times$ MIC resulted in prominent bulges and protrusions, although the hyphal surface remained smooth. With $2 \times$ MIC Jarrah (Barnes 10+) honey, hyphae became shrunken and collapsed and their surface appeared rough and damaged.

With the addition of catalase, Jarrah (Barnes 10+) honey at $1 \times$ and $2 \times$ MIC caused hyphae to bulge with a similar appearance to those treated with Jarrah (Barnes 10+) honey at $1 \times$ MIC. There was no evidence of the collapsing seen with $2 \times$ MIC Jarrah (Barnes $10+$ ) honey without catalase (Figure 3). When treated with Synthetic $\mathrm{H}_{2} \mathrm{O}_{2}$ Honey containing $56 \mu \mathrm{M} \mathrm{H}_{2} \mathrm{O}_{2}$, hyphae developed rough surfaces and some collapsing was seen. Some bulging was also present, but this was at a lower frequency than what was seen with Jarrah (Barnes 10+) honey and honey plus catalase treatments. These hyphal deformities suggest that low concentrations of $\mathrm{H}_{2} \mathrm{O}_{2}$ damage the surface of mature T. rubrum hyphae and that other stressors may be present in Jarrah (Barnes 10+) honey that cause the ballooning morphology.

\section{Discussion}

Tineas are the most common fungal infections globally, and their incidence is rising [1-3]. The limitations of current systemic and topical antifungal treatments have led to renewed interest in natural alternatives, including honey. Certain unique floral honeys from Australia have particularly high antimicrobial activity that is mediated by $\mathrm{H}_{2} \mathrm{O}_{2}$ and could be therapeutically useful for fungal infections [21]. This study aimed to characterize the activity of Australian jarrah honey against dermatophyte fungi.

\subsection{Many Fungal Dermatophyte Species Are Highly Susceptible to Jarrah Honey}

The $\mathrm{H}_{2} \mathrm{O}_{2}$-producing natural honeys tested in this study exhibited high antifungal activity against the six dermatophyte species (Tables 1 and 2). Fungi are generally more susceptible to the action of $\mathrm{H}_{2} \mathrm{O}_{2}$-type honeys than to Leptospermum (manuka) honey, where activity is dependent on MGO [8,19], and filamentous fungi such as Aspergillus, Penicillium, Microsporum [26], and Trichophyton [27] have been found to have greater sensitivity to honey than Candida and Saccharomyces yeasts $[26,27]$. In the limited studies that have included them, dermatophytes appear to be particularly susceptible to honey activity $[20,26]$; and compared to our previous work on Candida species that also tested jarrah honey the MICs for the dermatophytes tested here are 10-fold lower [8].

The dermatophytes appeared substantially more susceptible to jarrah honey than has been reported for other $\mathrm{H}_{2} \mathrm{O}_{2}$-producing honeys, where MICs have ranged from 5-39\% $(v / v)[19,20]$. Our results are in contrast to a recent study of a commercial jarrah honey, however, which had no activity against Trichophyton mentagrophytes and T. rubrum [28]. $\mathrm{H}_{2} \mathrm{O}_{2}$-producing honeys can be highly variable in activity, which can be influenced by age, processing and storage conditions as well as bee health and geographic factors, and even fresh and unprocessed samples can range from very high to negligible activity [21,29]. However, if stored correctly, highly active jarrah honey samples can retain therapeutically useful activity for many years [22]. Given this apparent hyper-susceptibility to jarrah honey and the fact that dermatophytes mostly cause topical infections, our findings suggest that superficial tineas could be treated effectively using ointments or gels that incorporate active jarrah honey.

3.2. $\mathrm{H}_{2} \mathrm{O}_{2}$ Production Is Necessary but Not Sufficient for the Inhibition of Dermatophyte Fungi by Jarrah Honey

The addition of catalase dramatically reduced the activity of Jarrah (Barnes 10+) honey, indicating that $\mathrm{H}_{2} \mathrm{O}_{2}$ production is critical for antifungal action (Table 2). However, the level 
of antifungal activity of the various honey samples did not correlate with their level of $\mathrm{H}_{2} \mathrm{O}_{2}$ production, and the amount of $\mathrm{H}_{2} \mathrm{O}_{2}$ estimated to be present in Jarrah (Barnes 10+) at the MIC was $~ 15$-fold lower than the level of $\mathrm{H}_{2} \mathrm{O}_{2}$ needed to inhibit T. rubrum, even when taking inhibition of the HRP assay into account (Table S1; Figure 1a). Furthermore, unlike whole Jarrah (Barnes 10+) honey, artificial honey spiked with $\mathrm{H}_{2} \mathrm{O}_{2}$ at a similar level did not inhibit the germination of conidia (Figure 1a,b). This suggests that $\mathrm{H}_{2} \mathrm{O}_{2}$ alone is not sufficient for inhibition and other factors influence the antifungal effect of jarrah honey.

Studies of the antibacterial effect of honey have similarly found the concentration of hydroxyl radicals to be much lower than what is expected based on their MIC values [30]. Potential synergistic compounds that might be present in Jarrah (Barnes 10+) include polyphenols [31,32], antimicrobial peptides [33], Maillard reaction products [34], and gluconic acid [35]. Contamination of honey with antibiotics and antifungals is also a possibility, however, jarrah grows in native forests that are not subjected to agricultural sprays, and as jarrah is a high-value product, beekeepers ensure they place their hives away from other forage. In addition, Australian honey is produced under strict guidelines for chemical residues and subjected to rigorous surveillance testing, and compliance is very high. Fungicides would also persist with the addition of catalase, however, almost all the antifungal activity was lost when the honey samples were treated with catalase (Table 2). Alternatively, the inhibition of the $\mathrm{HRP} / o$-dianisidine assay may have been greater than we calculated, causing the level of $\mathrm{H}_{2} \mathrm{O}_{2}$ in Jarrah (Barnes 10+) honey to be underestimated, which has been noted in other studies [21,24,32].

3.3. The Antifungal Activity of Jarrah Honey Appears to Be Mediated on the Surface of T. rubrum Hyphae, Causing Deformities and Hyphal Collapse

Scanning electron microscopy of mature T. rubrum hyphae following honey treatment revealed regions with visible swelling, bulging, and collapse (Figure 3). This damage to the hyphal surface increased with honey concentration and did not appear to be due to $\mathrm{H}_{2} \mathrm{O}_{2}$ as it also occurred in the presence of catalase (Figure 3). Severe hyphal collapse was apparent following treatment with $2 \times$ MIC Jarrah (Barnes 10+) honey, while treatment with artificial honey containing $56 \mu \mathrm{M} \mathrm{H}_{2} \mathrm{O}_{2}$ (estimated to be present in $2 \times$ MIC of Jarrah [Barnes 10+] honey) caused only minor hyphal collapse and surface roughening. As above, these findings suggest that $\mathrm{H}_{2} \mathrm{O}_{2}$ production in Jarrah (Barnes 10+) honey is necessary but not sufficient for its high antifungal activity against T. rubrum, and that there are other synergizing agents present.

The observed hyphal changes in T. rubrum are consistent with observations from other antifungal studies that have noted hyphal bulging leading to severe mycelial collapse [36-38]. The authors speculated that the cell membrane or wall becomes weakened due to direct damage, causing the structures to bulge and eventually, with lethal treatment, collapse [36-38]. In bacteria, treatment with either manuka or $\mathrm{H}_{2} \mathrm{O}_{2}$-producing honey produces changes to the surface structure including blebs and furrows, along with an increase in cell size $[39,40]$. This damage could be due to antimicrobial peptides present in honey, for example bee-defensin 1 [33], as these are known to elicit their cytotoxic effects through destruction of the cell membrane resulting in visible surface roughening, cellular leakage and regions of collapse [41,42].

Surprisingly, fluorescent redox dyes were unable to detect internal oxidative stress in mature hyphae following treatment with inhibitory and sub-inhibitory concentrations of honey (Figure 2). Antifungal agents that damage and kill cells normally activate stress response pathways [43-45], however, stress pathway down-regulation has been observed following synergistic treatments that seem to disrupt the normal stress response [46]. Yeast cells treated with propolis (a resinous substance produced by bees and containing beeswax and plant matter) show increased oxidative stress after 5-10 min [47]. In cancer cells, however, no oxidative stress was observed following honey treatment suggesting that cellular apoptosis occurred through a ROS-independent cellular pathway [48]. Together, these results suggest that the antifungal mechanism of honey is largely mediated at the hyphal surface, which is rapidly damaged without invoking intracellular ROS. 


\section{Conclusions}

Our study indicates that jarrah honey has unique antifungal attributes that work to inhibit and kill dermatophytes, making it a potentially promising candidate for the treatment of tineas. Remarkably low concentrations of jarrah honey were able to inhibit conidial germination and cause significant damage to mature hyphae in vitro. Although $\mathrm{H}_{2} \mathrm{O}_{2}$ production was critical for antifungal activity, the level present in Jarrah (Barnes 10+) honey was too low to account for its potent activity toward dermatophytes, suggesting it may possess agents that augment the killing caused by peroxide damage. Further research aimed at fractionating jarrah honey samples could identify these potential synergists and enable rapid screening of honey samples for high activity. In vivo studies are now needed to determine whether this potent antifungal activity of jarrah honey translates to mycological cure in clinical settings.

\section{Materials and Methods}

\subsection{Dermatophyte Cultures}

Dermatophyte species isolated from clinical specimens were sourced from the collection at RMIT University, Melbourne. Isolates were sub-cultured onto potato dextrose agar (PDA) plates from PDA slants and were incubated at $30^{\circ} \mathrm{C}$ until sufficient conidiation was observed. Conidia were collected by washing colonies with $1 \mathrm{~mL}$ sterile phosphate buffered saline (PBS) while gently abrading the surface with the tip of a pipette. The PBS was then recovered and placed in microcentrifuge tube for $10 \mathrm{~min}$ to allow particulate matter and hyphal fragments to settle. The upper $600 \mu \mathrm{L}$ was then decanted into a fresh microcentrifuge tube. The concentration of conidia in the suspension was determined using a hemocytometer, and standardized conidia concentrations were prepared in RPMI-1640 (Sigma Aldrich, St. Louis, MI, USA, Cat. No. R6504) for antifungal testing, or PBS for other tests.

\subsection{Honey Samples}

Six honey samples were tested for antifungal activity (Table 3). Three samples were collected during an Australian honey survey [21] where they were found to have antimicrobial activity and moderate-to-high levels of peroxide-based activity. One sample was from the University of Technology Sydney honey collection and was derived from Leptospermum speciosum, with non-peroxide-based activity that is assumed to be due to MGO. Two honeys were sourced in larger volumes for extended testing: Jarrah (Barnes 10+), a commercially available edible honey with relatively low peroxide activity (marketed as Barnes Naturals Active Jarrah Honey) and purchased in 2019 [22], and Jarrah 2017, a raw jarrah honey sample collected in Northcliff WA Australia in 2017 with high peroxide activity. All honey samples were stored in the dark at $4{ }^{\circ} \mathrm{C}$. Prior to testing, the honey samples were diluted to $50 \%(w / v)$ in $\mathrm{H}_{2} \mathrm{O}$ and incubated at $35^{\circ} \mathrm{C}$ with shaking at $180 \mathrm{rpm}$ for 20 min to aid mixing. Then were then vortexed and filter sterilized using a $0.22 \mu \mathrm{m}$ syringe filter (Millex, Duluth, GA, USA, Cat. No. SLG033) and were used on the day of testing.

\subsection{Quantification of $\mathrm{H}_{2} \mathrm{O}_{2}$ Production}

$\mathrm{H}_{2} \mathrm{O}_{2}$ produced by the honey samples were previously quantified [22] using a recently described, standardized horseradish peroxidase (HRP)/o-dianisidine colorimetric assay [25]. The assay was conducted over a $24 \mathrm{~h}$ period with the maximum level of production recorded (Table 3 ); data are the mean \pm SEM of two biological replicates.

In Jarrah (Barnes 10+) honey, our previous study found an average maximum of $136 \mu \mathrm{M}$ at $1 \mathrm{~h}$ post dilution that diminished over time [22]. When spiked with $\mathrm{H}_{2} \mathrm{O}_{2}$ to give a final concentration of $500 \mu \mathrm{M}$, only $188 \mu \mathrm{M}$ could be recovered after $2 \mathrm{~h}$ of incubation, suggesting either the HRP reaction had been inhibited or the $\mathrm{H}_{2} \mathrm{O}_{2}$ was being degraded during incubation. Considering this potential masking or loss of $312 \mu \mathrm{M}^{\circ} \mathrm{H}_{2} \mathrm{O}_{2}$ production, we estimated $25 \%(w / v)$ Jarrah (Barnes $10+$ ) honey to produce $\sim 448 \mu \mathrm{M}$ of 
$\mathrm{H}_{2} \mathrm{O}_{2}$ at $1 \mathrm{~h}$ [22]. This estimate was used to approximate the amount of $\mathrm{H}_{2} \mathrm{O}_{2}$ present in minimum inhibitory concentration levels of Jarrah (Barnes 10+) honey.

\subsection{Honey Component Solutions}

Various components of honey were tested by creating a series of honey component solutions (Table 4). Artificial honey, which was used as an osmotic control, was made by dissolving $2.29 \mathrm{~g} / \mathrm{mL}$ fructose, $2.07 \mathrm{~g} / \mathrm{mL}$ glucose, and $0.16 \mathrm{~g} / \mathrm{mL}$ sucrose in $\mathrm{dH}_{2} \mathrm{O}$ and incubating at $40{ }^{\circ} \mathrm{C}$ for several days until the sugars were fully dissolved it became homogenous in consistency. It was then diluted to $50 \%(w / v)$ with $\mathrm{dH}_{2} \mathrm{O}$, incubated at $35^{\circ} \mathrm{C}$ with shaking and filter sterilized as above. This was used to balance the level of sugar in diluted samples of the Jarrah (Barnes 10+) honey to be consistently equal to $10 \%$ honey (referred to in Table 4 as "Jarrah (Barnes 10+) + artificial honey"). A series of Synthetic $\mathrm{H}_{2} \mathrm{O}_{2}$ Honey solutions were also prepared by adding together the $50 \%(w / v)$ artificial honey solution, $2 \times$ RPMI-1640 (Sigma Aldrich, St. Louis, MI, USA, Cat. No. R6504) and 3\% $\mathrm{H}_{2} \mathrm{O}_{2}$ (Sigma Aldrich, Cat. No. 88597), to achieve a final concentration of $10 \%(w / v)$ artificial honey and a range of concentrations of $\mathrm{H}_{2} \mathrm{O}_{2}$ based on the MIC for T. rubrum (Table 4). All the honey solutions were freshly prepared on the day of the experiments where they were used.

\subsection{Minimum Inhibitory Concentrations (MICs) and Minimum Fungicidal Concentrations (MFCs) of Honey}

Susceptibility testing was conducted in accordance with the Clinical and Laboratory Standards Institute (CLSI) [49]. Honey and $\mathrm{H}_{2} \mathrm{O}_{2}$ solutions were made freshly on the day of testing. All tests containing honey or $\mathrm{H}_{2} \mathrm{O}_{2}$ were conducted in subdued lighting.

Minimum inhibitory concentrations (MIC) were determined for the different honey samples, $\mathrm{H}_{2} \mathrm{O}_{2}$ in solution (Sigma Aldrich, St. Louis, MI, USA, Cat. No. 88597), and artificial honey, with the various dermatophyte species (Table 1). Ninety-six-well, flat-bottomed plates were used for all antifungal testing. Conidial suspensions of each dermatophyte species were prepared in RPMI-1640 to a concentration of 1-3 $\times 10^{4}$ conidia $/ \mathrm{mL}$. Two-fold serial dilutions of the different honey or $\mathrm{H}_{2} \mathrm{O}_{2}$ solutions were prepared in RPMI-1640 to give final concentrations of $0.25-5 \%(w / v)$ Jarrah 2017 honey, $0.25-50 \%(w / v)$ Leptospermum and artificial honey, and $0.002-2.00 \mathrm{mM} \mathrm{H}_{2} \mathrm{O}_{2}$. Twenty microlitres of the conidial suspension was added to $180 \mu \mathrm{L}$ of each honey or $\mathrm{H}_{2} \mathrm{O}_{2}$ dilution to give a final concentration of 1-3 $\times 10^{3}$ conidia/mL. Voriconazole (VOR; Sigma Aldrich, St. Louis, MI, USA, Cat. No. D8418) was used as a control antifungal agent and tested alongside the honey samples. A stock solution of $400 \mu \mathrm{g} / \mathrm{mL}$ VOR was prepared in DMSO and diluted in RPMI-1640 to give final 2-fold dilutions from $0.008-4 \mu \mathrm{g} / \mathrm{mL}$. Conidia suspensions were added as above to a final concentration of 1-3 $\times 10^{3}$ conidia/ $\mathrm{mL}$. To test the effect of $\mathrm{H}_{2} \mathrm{O}_{2}$ on activity in the honey samples where peroxide activity was detected (Table 3 ), honey samples were serially diluted to final concentrations of $0.05-25 \%(w / v)$ as above and a parallel MIC was performed where the RPMI-1640 medium contained $7000 \mathrm{U} / \mathrm{mL}$ catalase (Sigma Aldrich, St. Louis, MI, USA, Cat. No. SRE0041). The plates were incubated for $96 \mathrm{~h}$ at $30^{\circ} \mathrm{C}$ under humidified conditions. Positive (no inhibitory agent) and negative (no fungi) controls were included on each plate.

The lowest concentration of the antimicrobial agent to inhibit growth was defined as the minimum inhibitory concentration (MIC), with $\mathrm{MIC}_{100}$ and $\mathrm{MIC}_{80}$ indicating no growth or an $80 \%$ reduction in growth, respectively. MICs were determined visually by comparison with the positive and negative growth controls. The minimum fungicidal concentration (MFC) was determined by spotting $50 \mu \mathrm{L}$ aliquots from wells with no apparent growth onto SDA plates and incubating these at $30^{\circ} \mathrm{C}$ for $96 \mathrm{~h}$. The lowest honey concentration producing less than three colonies, which corresponds to killing $\geq 99.9 \%$ of the inoculum, was defined as the MFC. MICs and MFCs were determined as the mean $\pm \mathrm{SEM}$ (if variation was present) of two biological replicates for Table 1 and three biological replicates for Table 2. 


\subsection{Microscopic Analysis of T. rubrum Conidia Treated with Honey}

Trichophyton rubrum was chosen for further investigation as it is the most commonly isolated dermatophyte in superficial infections globally [50]. Filter-sterilized solutions of $50 \%(w / v)$ Jarrah (Barnes $10+$ ) honey or artificial honey were prepared in $\mathrm{dH}_{2} \mathrm{O}$ and then added to $2 \times$ RPMI- 1640 to create the dilutions series of Jarrah (Barnes 10+) + artificial honey and Synthetic $\mathrm{H}_{2} \mathrm{O}_{2}$ Honey solutions based on the MICs for T. rubrum (Table 4). To determine if the low levels of $\mathrm{H}_{2} \mathrm{O}_{2}$ predicted to be produced in Jarrah (Barnes 10+) honey were able to inhibit conidia, Synthetic $\mathrm{H}_{2} \mathrm{O}_{2}$ Honey solutions containing $0,25,50$, 100, 200 and $400 \mu \mathrm{M} \mathrm{H}_{2} \mathrm{O}_{2}$ were also created (Table 4).

To assess how honey affected the germination of T. rubrum conidia, sterile square $(22 \times 22 \mathrm{~mm})$ microscope coverslips (Trajan Scientific and Medical, Ringwood, Australia, Cat. No. 471112222) were placed into each well of a six-well flat-bottomed plate (Corning Costar, Corning, AZ, USA, Cat. No. 3516) and covered with $1.5 \mathrm{~mL}$ of the appropriate treatment solution. Each well was then inoculated with $500 \mu \mathrm{L}$ of $8 \times 10^{4}$ conidia/mL T. rubrum conidia in PBS (prepared as outlined in Section 5.1) to give a final concentration of $2 \times 10^{4}$ conidia $/ \mathrm{mL}$. The plates were incubated at $30^{\circ} \mathrm{C}$ for $48 \mathrm{~h}$. Following this, coverslips were rinsed in PBS, then stained with $1 \mathrm{~mL}$ of $50 \mu \mathrm{M}$ calcofluor white (Sigma Aldrich, St. Louis, MI, USA, Cat. No. 18909) in PBS and incubated for 1 min protected from light.

Conidia and germinating hyphae were visualized using the DAPI filter set of an Olympus BX51 microscope (Shinjuku, Japan), and images were taken using the $40 \times$ objective. The length of conidia and hyphae were measured using Fiji Image J software [51], where the straight-line tool connected the ends of structures.

\subsection{Detection of Reactive Oxygen Species in T. rubrum Hyphae Treated with Jarrah Honey}

A similar method to that outlined in Section 5.6 was used to detect oxidative stress in T. rubrum hyphae treated with honey. A square sterile $(22 \times 22 \mathrm{~mm})$ coverslip was placed into each well of a 6-well flat-bottomed plate, which was then inoculated with $2 \times 10^{4}$ conidia/mL in $3 \mathrm{~mL}$ RPMI-1640. The plates were incubated at $30^{\circ} \mathrm{C}$ for $24 \mathrm{~h}$ to generate hyphae, and the media was then removed and replaced with Jarrah (Barnes $10+$ ) + artificial honey at $\frac{1}{2} \times$ MIC, $1 \times$ MIC, $2 \times$ MIC and $4 \times$ MIC (Table 4). Synthetic $\mathrm{H}_{2} \mathrm{O}_{2}$ Honey was used as a positive control for ROS production, with $\mathrm{H}_{2} \mathrm{O}_{2}$ at $56 \mu \mathrm{M}$ (equivalent to $2 \times$ MIC in Jarrah (Barnes $10+)$ honey; see Section 5.3), $\frac{1}{2} \times$ MIC $(215 \mu \mathrm{M})$ or $4 \times$ MIC $(1720 \mu \mathrm{M}$; Table 4$)$. The hyphal cultures were incubated at $30^{\circ} \mathrm{C}$ for 6 or $14.5 \mathrm{~h}$ to detect both early and final ROS production. Following incubation, the media was removed by aspiration and coverslips with adherent hyphae were rinsed once in PBS and then incubated in $1 \mathrm{~mL}$ RPMI-1640 medium containing $50 \mu \mathrm{M}$ calcofluor white and $10 \mu \mathrm{M} 2^{\prime}, 7^{\prime}$-dichlorofluorescin diacetate (DCFDA) (Sigma-Aldrich, St. Louis, MI, USA, Cat. No. D6883), or $50 \mu \mathrm{M}$ calcofluor white and $5 \mu \mathrm{M}$ CellROX Green (Sigma-Aldrich, St. Louis, MI, USA, Cat. No. C10444), for $30 \mathrm{~min}$ at $30^{\circ} \mathrm{C}$ with shaking at $45 \mathrm{rpm}$. The stains were removed by aspiration and coverslips were then rinsed three times with PBS and imaged using an Olympus BX51 microscope equipped with a DAPI or FITC filter. Exposure was kept consistent at $200 \mathrm{~ms}$. To calculate the fluorescence intensity of DCFDA staining, each calcofluor white-stained hyphal structure seen under the DAPI filter was outlined in Image J and the area measured. This hyphal outline was then copied onto the image of the hypha taken under the FITC filter and the integrated density of fluorescence from the outlined area was measured. Three background readings were taken around the perimeter of the hypha in the FITC image. The corrected total cell fluorescence (CTCF) for DCFDA was determined using the following equation:

CTCF $=$ integrated density $-($ area of hyphae $\times$ mean fluorescence of background $)$

\subsection{Scanning Electron Microscopy of T. rubrum Hyphae Treated with Jarrah Honey}

Scanning electron microscopy (SEM) was used to reveal hyphal changes in greater detail. Round Thermanox coverslips (13 mm diameter) (ProSciTech, Thuringowa, Australia, Cat. No. GL083) were first sterilized by washing in $90 \%$ acetone then Milli-Q $\mathrm{H}_{2} \mathrm{O}$ and 
were then incubated in 1\% polyethyleneimine (Sigma Aldrich, St. Louis, MI, USA, Cat. No. 03880) and rinsed twice in Milli-Q $\mathrm{H}_{2} \mathrm{O}$. Slides were left to dry at room temperature for $3 \mathrm{~h}$. Treated coverslips were then placed into six wells of a 24-well flat-bottomed plate that each contained $500 \mu \mathrm{L}$ RPMI-1640 medium containing $4 \times 10^{4}$ T. rubrum conidia/mL. Plates were incubated for $24 \mathrm{~h}$ at $30^{\circ} \mathrm{C}$, after which the media was removed and replaced with $500 \mu \mathrm{L}$ of each of the following treatment solutions: $1 \times$ MIC Jarrah (Barnes 10+) + artificial honey \pm 7000 U catalase; $2 \times$ MIC Jarrah (Barnes 10+) + artificial honey \pm 7000 U catalase; Synthetic $\mathrm{H}_{2} \mathrm{O}_{2}$ Honey containing $56 \mu \mathrm{M} \mathrm{H}_{2} \mathrm{O}_{2}$ (predicted to be present in $2 \times$ MIC of Jarrah [Barnes $10+]$ honey); for all treatments osmolarity was standardized to a final concentration of $10 \%$ $(w / v)$ honey (Table 4). A control treatment contained $500 \mu \mathrm{L} \mathrm{10 \%} \mathrm{(w/v)} \mathrm{artificial} \mathrm{honey} \mathrm{+}$ $7000 \mathrm{U}$ catalase. Following a $24-\mathrm{h}$ incubation at $30{ }^{\circ} \mathrm{C}$, treatment solutions were removed by aspiration and coverslips were then washed in $0.1 \mathrm{M}$ phosphate buffer (PB). Slides were then fixed by adding $250 \mu \mathrm{L}$ of primary fixative containing $2.5 \%$ glutaraldehyde (ChemSupply, Gillman, Australia, Cat. No. EA043) and 2\% paraformaldehyde (Sigma Aldrich, St. Louis, MI, USA, Cat. No. 47608) in 0.1 M PB to each well, with overnight incubation at $4{ }^{\circ} \mathrm{C}$.

The primary fixative solution was removed by aspiration and coverslips were then rinsed three times for 5-min with $500 \mu \mathrm{L}$ of $0.1 \mathrm{M}$ PB. Rinsed coverslips were incubated in $\sim 250 \mu \mathrm{L}$ (enough to completely submerge coverslip) of secondary fixative containing 2\% $(v / v) \mathrm{OsO}_{4}$ (ProSciTech, Thuringowa, Australia, Cat. No. C011) in $0.1 \mathrm{M} \mathrm{PB}$, for $1 \mathrm{~h}$. This was removed and followed with three $\times 5$-min washes with $250 \mu \mathrm{L}$ of Milli-Q $\mathrm{H}_{2} \mathrm{O}$. An ethanol concentration gradient was used to dehydrate fixed samples consisting of two treatments of 30, 50 and $70 \%(v / v)$ ethanol, then three treatments of 95 and $100 \%$ $(v / v)$ ethanol. Further chemical desiccation of samples was conducted by adding $250 \mu \mathrm{L}$ hexamethyldisilazane (HMDS) (Sigma Aldrich, St. Louis, MI, USA, Cat. No. 440191) for 2 min. HMDS was removed and samples were allowed to dry in the fume hood. Coverslips containing desiccated hyphae were mounted onto metallic stubs and an Emitech K550X sputter coater (Paris, France) covered them in gold at $2 \mathrm{~mA}$ for $2 \mathrm{~min}$. Samples were visualized under $15 \mathrm{kV}$ using a JEOL JCM-6000 benchtop scanning electron microscope (Tokyo, Japan).

\subsection{Statistical Analysis}

Hyphal length measurements and fluorescence intensity data from experiments 4.6 and 4.7, respectively, were analyzed in GraphPad Prism (San Diego, CA, USA). The D'AgostinoPearson omnibus normality test was conducted on hyphal germination and fluorescence data sets to determine whether the data exhibited a Gaussian distribution. As all data had a non-Gaussian distribution, they were analyzed using the non-parametric Kruskal-Wallis test. Significant results were followed up with a Dunn's multiple comparison test that determined the treatment groups that were significantly different to each other. In all figures, asterisks denote the following: ${ }^{*} p \leq 0.05^{* *} p \leq 0.01,{ }^{* * *} p \leq 0.001,{ }^{* * * *} p \leq 0.0001$.

Supplementary Materials: The following are available online at https:/ / www.mdpi.com/2076-081 7/10/2/194/s1, Table S1: The estimated concentration of $\mathrm{H}_{2} \mathrm{O}_{2}$ present in each jarrah (Barnes 10+) honey dilution based on the HRP assay.

Author Contributions: Funding acquisition, E.H. and D.C.; Investigation, A.G. and K.K.; Methodology, A.G., K.K. and D.C.; Project administration, D.C.; Resources, S.H., N.C., E.H. and D.C.; Supervision, N.C. and D.C.; Visualization, A.G.; Writing-original draft, A.G. and D.C.; Writingreview \& editing, K.K., S.H., N.C., E.H. and D.C. All authors have read and agreed to the published version of the manuscript.

Funding: This research was funded by the Honey Bee and Pollination Program through AgriFutures Australia grant number PRJ-009186. This program was previously known as the Australian Rural Industries Research and Development Corporation.

Institutional Review Board Statement: Not applicable. 
Informed Consent Statement: Not applicable.

Acknowledgments: We would like to thank Kenya Fernandes from the University of Sydney for her scanning electron microscopy expertise and guidance, and the Australian Centre for Microscopy and Microanalysis at the University of Sydney for use of their facilities. We thank Capilano and the New South Wales beekeepers who provided the honey samples used in this work. Thanks to Kerry Weeks from Concord Hospital, Sydney and Catriona Halliday from Westmead Hospital, Sydney for their support with fungal cultures.

Conflicts of Interest: The authors declare no conflict of interest.

\section{References}

1. Graser, Y.; Scott, J.; Summerbell, R. The new species concept in dermatophytes-A polyphasic approach. Mycopathologia 2008, 166, 239-256. [CrossRef] [PubMed]

2. $\quad$ Elewski, B.E.; Rich, P.; Tosti, A.; Pariser, D.M.; Scher, R.; Daniel, R.C.; Gupta, A.K. Onchomycosis: An overview. J. Drugs Dermatol. 2013, 12, 96-103.

3. Havlickova, B.; Czaika, V.A.; Friedrich, M. Epidemiological trends in skin mycoses worldwide. Mycoses 2008, 51, 2-15. [CrossRef] [PubMed]

4. Achterman, R.R.; White, T.C. A foot in the door for dermatophyte research. PLoS Path. 2012, 8, e1002564. [CrossRef] [PubMed]

5. Kaur, I.P.; Kakkar, S. Topical delivery of antifungal agents. Expert Opin. Drug Deliv. 2010, 7, 1303-1327. [CrossRef] [PubMed]

6. Gupta, A.K.; Chow, M.; Daniel, C.R.; Aly, R. Treatments of tinea pedis. Dermatol. Clin. 2003, 21, 431-462. [CrossRef]

7. Burlando, B.; Cornara, L. Honey in dermatology and skin care: A review. J. Cosmet. Dermatol. 2013, 12, 306-313. [CrossRef]

8. Irish, J.; Carter, D.A.; Shokohi, T.; Blair, S.E. Honey has an antifungal effect against Candida species. Med. Mycol. 2006, 44, $289-291$. [CrossRef] [PubMed]

9. Kwakman, P.H.S.; te Velde, A.A.; de Boer, L.; Vandenbroucke-Grauls, C.M.J.E.; Zaat, S.A.J. Two major medicinal honeys have different mechanisms of bactericidal activity. PLOS ONE 2011, 6, e17709. [CrossRef] [PubMed]

10. Molan, P.C. The antibacterial activity of honey: 2. Variation in the potency of the antibacterial activity. N. Z. Bee World 1992, 73, 59-76. [CrossRef]

11. Carter, D.A.; Blair, S.E.; Cokcetin, N.N.; Bouzo, D.; Brooks, P.; Schothauer, R.; Harry, E.J. Therapeutic manuka honey: No longer so alternative. Front. Microbiol. 2016, 7, 11. [CrossRef] [PubMed]

12. Kwakman, P.H.S.; Zaat, S.A.J. Antibacterial components of honey. IUBMB Life 2012, 64, 48-55. [CrossRef]

13. Brudzynski, K.; Miotto, D. Honey melanoidins: Analysis of the compositions of the high molecular weight melanoidins exhibiting radical-scavenging activity. Food Chem. 2011, 127, 1023-1030. [CrossRef]

14. Weston, R.J. The contribution of catalase and other natural products to the antibacterial activity of honey: A review. Food Chem. 2000, 71, 235-239. [CrossRef]

15. White, J.W.; Subers, M.H.; Schepartz, A.I. The identification of inhibine, the antibacterial factor in honey, as hydrogen peroxide and its origin in a honey glucose-oxidase system. BBA 1963, 73, 57-70. [CrossRef]

16. Adams, C.J.; Manley-Harris, M.; Molan, P.C. The origin of methylglyoxal in New Zealand manuka (Leptospermum scoparium) honey. Carbohydr. Res. 2009, 344, 1050-1053. [CrossRef] [PubMed]

17. Cokcetin, N.; Pappalardo, M.; Campbell, L.T.; Brooks, P.; Carter, D.A.; Blair, S.E.; Harry, E.J. The antibacterial activity of Australian Leptospermum honey correlates with methylglyoxal levels. PLoS ONE 2016, 11, e0167780. [CrossRef]

18. Allen, K.L.; Molan, P.C.; Reid, G.M. A survey of the antibacterial activity of some New Zealand honeys. J. Pharm. Pharmacol. 1991, 43, 817-822. [CrossRef]

19. Brady, N.F.; Molan, P.C.; Harfoot, C.G. The sensitivity of dermatophytes to the antimicrobial activity of manuka honey and other honey. Pharm. Pharmacol. Commun. 1996, 2, 471-473. [CrossRef]

20. Katiraee, F.; Mahmodi, R.; Mardani, K.; Babaei, E. Antifungal activity of Iranian honeybees against Candida, Aspergillus species and Trichophyton rubrum. J. Food Process. Preserv. 2014, 38, 2078-2082. [CrossRef]

21. Irish, J.; Blair, S.; Carter, D.A. The antibacterial activity of honey derived from Australian flora. PLoS ONE 2011, 6, e18229. [CrossRef]

22. Guttentag, A.; Krishnakumar, K.; Cokcetin, N.; Harry, E.; Carter, D.A. Factors affecting the production and measurement of hydrogen peroxide in honey samples. Access Microbiol. 2021. [CrossRef]

23. Giorgio, M.; Trinei, M.; Migliaccio, E.; Pelicci, P.G. Hydrogen peroxide: A metabolic by-product or a common mediator of ageing signals? Nat. Rev. Mol. Cell Biol. 2007, 8, 722-728. [CrossRef]

24. Yagi, H.; Tan, J.; Tuan, R.S. Polyphenols suppress hydrogen peroxide-induced oxidative stress in human bone-marrow derived mesenchymal stem cells. J. Cell. Biochem. 2013, 114, 1163-1173. [CrossRef]

25. Lehmann, D.M.; Krishnakumar, K.; Batres, M.A.; Hakola-Parry, A.; Cokcetin, N.; Harry, E.; Carter, D.A. A cost-effective colourimetric assay for quantifying hydrogen peroxide in honey. Access Microbiol. 2019, 1. [CrossRef]

26. Anyanwu, C. Investigation of in vitro antifungal activity of honey. JMPR 2012, 6, 3512-3516. [CrossRef]

27. Brady, N.; Molan, P.; Bang, L. A survey of non-manuka New Zealand honeys for antibacterial and antifungal activities. J. Apic. Res. 2004, 43, 47-52. [CrossRef] 
28. Anand, S.; Deighton, M.; Livanos, G.; Pang, E.C.K.; Mantri, N. Agastache honey has superior antifungal activity in comparison with important commercial honeys. Sci. Rep. 2019, 9, 18197. [CrossRef]

29. Chen, C.; Campbell, L.T.; Blair, S.E.; Carter, D.A. The effect of standard heat and filtration processing procedures on antimicrobial activity and hydrogen peroxide levels in honey. Front. Microbiol. 2012, 3, 265. [CrossRef]

30. Brudzynski, K.; Abubaker, K.; Wang, T. Powerful bacterial killing by buckwheat honeys is concentration-dependent, involves complete DNA degradation and requires hydrogen peroxide. Front. Microbiol. 2012, 3, 242. [CrossRef]

31. Bucekova, M.; Buriova, M.; Pekarik, L.; Majtan, V.; Majtan, J. Phytochemicals-mediated production of hydrogen peroxide is crucial for high antibacterial activity of honeydew honey. Sci. Rep. 2018, 8, 9061. [CrossRef] [PubMed]

32. Anand, S.; Pang, E.; Livanos, G.; Mantri, N. Characterization of physico-chemical properties and antioxidant capacities of bioactive honey produced from Australian grown Agastache rugosa and its correlation with colour and poly-phenol content. Molecules 2018, 23, 108. [CrossRef]

33. Kwakman, P.H.S.; te Velde, A.A.; de Boer, L.; Speijer, D.; Vandenbroucke-Grauls, C.; Zaat, S.A.J. How honey kills bacteria. FASEB J. 2010, 24, 2576-2582. [CrossRef] [PubMed]

34. Brudzynski, K.; Miotto, D. The relationship between the content of Maillard reaction-like products and bioactivity of Canadian honeys. Food Chem. 2011, 124, 869-874. [CrossRef]

35. Masoura, M.; Passaretti, P.; Overton, T.W.; Lund, P.A.; Gkatzionis, K. Use of a model to understand the synergies underlying the antibacterial mechanism of $\mathrm{H}_{2} \mathrm{O}_{2}$-producing honeys. Sci. Rep. 2020, 10, 17692. [CrossRef] [PubMed]

36. Jansen, T.; Borgers, M.; van de Ven, M.A.; Xhonneux, B.; Wouters, L.; van Gerven, F.; van Cutsem, J. The effects of saperconazole on the morphology of Candida albicans, Pityrosporum ovale and Trichophyton rubrum in vitro. J. Med. Vet. Mycol. 1991, 29, 293-303. [CrossRef]

37. Smijs, T.G.M.; Mulder, A.A.; Pavel, S.; Onderwater, J.J.M.; Koerten, H.K.; Bouwstra, J.A. Morphological changes of the dermatophyte Trichophyton rubrum after photodynamic treatment: A scanning electron microscopy study. Med. Mycol. 2008, 46, 315-325. [CrossRef]

38. Ghannoum, M.; Isham, N.; Henry, W.; Kroon, H.A.; Yurdakul, S. Evaluation of the morphological effects of TDT 067 (terbinafine in transfersome) and conventional terbinafine on dermatophyte hyphae in vitro and in vivo. Antimicrob. Agents Chemother. 2012, 56, 2530. [CrossRef] [PubMed]

39. Henriques, A.F.; Jenkins, R.E.; Burton, N.F.; Cooper, R.A. The effect of manuka honey on the structure of Pseudomonas aeruginosa. Eur. J. Clin. Microbiol. Infect. Dis. 2011, 30, 167-171. [CrossRef]

40. Nishio, E.K.; Ribeiro, J.M.; Oliveira, A.G.; Andrade, C.G.T.J.; Proni, E.A.; Kobayashi, R.K.T.; Nakazato, G. Antibacterial synergic effect of honey from two stingless bees: Scaptotrigona bipunctata Lepeletier, 1836, and S. postica Latreille, 1807. Sci. Rep. 2016, 6, 21641. [CrossRef]

41. Lv, Y.; Wang, J.; Gao, H.; Wang, Z.; Dong, N.; Ma, Q.; Shan, A. Antimicrobial properties and membrane-active mechanism of a potential $\alpha$-helical antimicrobial derived from cathelicidin PMAP-36. PLoS ONE 2014, 9, e86364. [CrossRef]

42. Fernandes, K.E.; Weeks, K.; Carter, D.A. Lactoferrin is broadly active against yeasts and highly synergistic with amphotericin B. Antimicrob. Agents Chemother. 2020, 64, e02284-19. [CrossRef]

43. Sokol-Anderson, M.L.; Brajtburg, J.; Medoff, G. Amphotericin B-induced oxidative damage and killing of Candida albicans. J. Infect. Dis. 1986, 154, 76-83. [CrossRef]

44. Sangalli-Leite, F.; Scorzoni, L.; Mesa-Arango, A.C.; Casas, C.; Herrero, E.; Soares Mendes Gianinni, M.J.; Rodríguez-Tudela, J.L.; Cuenca-Estrella, M.; Zaragoza, O. Amphotericin B mediates killing in Cryptococcus neoformans through the induction of a strong oxidative burst. Microb. Infect. 2011, 13, 457-467. [CrossRef]

45. Lai, Y.-W.; Pang, C.N.I.; Campbell, L.T.; Chen, S.C.A.; Wilkins, M.R.; Carter, D.A. Different pathways mediate amphotericinlactoferrin drug synergy in Cryptococcus and Saccharomyces. Front. Microbiol. 2019, 10, 2195. [CrossRef] [PubMed]

46. Pang, C.N.; Lai, Y.W.; Campbell, L.T.; Chen, S.C.; Carter, D.A.; Wilkins, M.R. Transcriptome and network analyses in Saccharomyces cerevisiae reveal that amphotericin B and lactoferrin synergy disrupt metal homeostasis and stress response. Sci. Rep. 2017, 7, 40232. [CrossRef]

47. de Castro, P.A.; Savoldi, M.; Bonatto, D.; Barros, M.H.; Goldman, M.H.; Berretta, A.A.; Goldman, G.H. Molecular characterization of propolis-induced cell death in Saccharomyces cerevisiae. Eukaryot. Cell 2011, 10, 398-411. [CrossRef] [PubMed]

48. Morales, P.; Haza, A.I. Antiproliferative and apoptotic effects of Spanish honeys. Pharmacogn. Mag. 2013, 9, 231-237. [CrossRef]

49. CLSI. Reference Method for Broth Dilution Antifungal Susceptibility Testing of Filamentous fungi: Approved Standard, 2nd ed.; CLSI document M28-A2; Clinical and Laboratory Standards Institute: Wayne, PA, USA, 2008.

50. Nenoff, P.; Krüger, C.; Ginter-Hanselmayer, G.; Tietz, H.J. Mycology-An update. Part 1: Dermatomycoses: Causative agents, epidemiology and pathogenesis. J. Dtsch. Dermatol. Ges. 2014, 12. [CrossRef]

51. Schindelin, J.; Arganda-Carreras, I.; Frise, E.; Kaynig, V.; Longair, M.; Pietzsch, T.; Preibisch, S.; Rueden, C.; Saalfeld, S.; Schmid, B.; et al. Fiji: An open-source platform for biological-image analysis. Nat. Methods 2012, 9, 676-682. [CrossRef] [PubMed] 